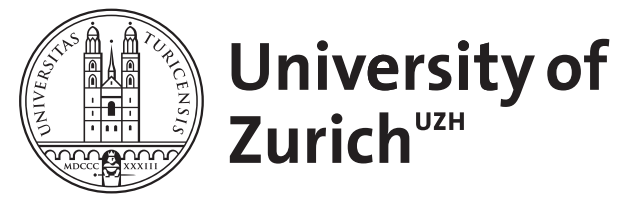
Archive

University of Zurich

University Library

Strickhofstrasse 39

CH-8057 Zurich

www.zora.uzh.ch

Year: 2015

Health of migrants: approaches from a public health ethics perspective

Wild, Verina ; Zion, Deborah ; Ashcroft, Richard

DOI: https://doi.org/10.1093/phe/phv017

Posted at the Zurich Open Repository and Archive, University of Zurich

ZORA URL: https://doi.org/10.5167/uzh-114990

Journal Article

Accepted Version

Originally published at:

Wild, Verina; Zion, Deborah; Ashcroft, Richard (2015). Health of migrants: approaches from a public health ethics perspective. Public Health Ethics, 8(2):107-109.

DOI: https://doi.org/10.1093/phe/phv017 


\title{
Health of migrants: Approaches from a public health ethics perspective
}

\author{
Verina Wild, Deborah Zion, Richard Ashcroft
}

"How do we know when it is dawn? When we have enough light to recognise, in the face of the stranger, that of our sister.

Middle Eastern Proverb, to be found on the Memorial for the SIEV X, commemorating asylum seekers drowned at sea. Canberra, Australia.

In 2013 a number of 230 million international migrants was estimated, of which 51.2 million people were forcibly displaced (UNHCR, 2014; United Nations, 2014). The majority of these refugees reside in the global South, in countries that have difficulties providing healthcare to their own citizens. However, in countries with functioning health care systems, there are also hundreds of thousands of people who are seeking refuge from brutal wars in the Middle East, and in the Horn of Africa. Additionally, an unknown number of undocumented migrants or temporary workers are on the move.

Despite the fact that Europe, the US and Australia have considerably more resources to support healthcare (amongst other social and economic benefits) than other reception countries such as Pakistan and Iran, there is little consensus between or within countries about an acceptable standard of healthcare for different migrant groups, such as undocumented migrants, asylum seekers, refugees and temporary workers. There is also considerable disagreement about how this healthcare might be accessed, or the philosophical and human rights positions that underpin discussions concerning access and delivery.

In this edition of Public Health Ethics we seek to address these concerns. Our conversation began in 2013 at an international symposium at the Brocher Foundation in Switzerland, in which a group of scholars, and experts from NGOs and International Organisations from five continents explored ethical issues related to different migrant groups and health. We focussed particularly on undocumented migrants, asylum seekers and refugees as some of those who can be rendered most vulnerable. The papers published here trace the arc of philosophical debates and practical issues related to one aspect of our discussions: access to health care. The papers by Brock, Dwyer, and Wild originate in papers presented at this symposium.

Henry Shue, Professor of Politics and International Relations at the University of Oxford, encapsulates the heart of our debate in his story of two men, Benny and Al. Benny is relatively wealthy, whereas $\mathrm{Al}$ is deprived of the most basic rights and goods. In his commentary on their situation, Shue asks the question: why should Benny, who shares neither culture nor any institutions with $\mathrm{Al}$, have a duty to protect and fulfil his rights?

Two interrelated questions emerge: Why do we owe duties to strangers? What should these duties look like? And following on for this, is health and healthcare in some way more important than other rights and goods that are fundamental to survival and the needs of a worthwhile life? 
The authors in the edition seek to answer these questions in different ways.

James Dwyer explores why societies have an ethical responsibility to care for and about the health of undocumented migrants. He develops a finely nuanced account of moral claims that are located in the normative middle ground between claims that people have as human beings and claims that they have as citizens. Focusing on the situation in the USA, he shows how adult migrants are used in the economic system and how child migrants are socialized in society. These social arrangements and practices give rise to social responsibilities to care for and about migrants, even migrants who lack official legal status.

Patricia Illingworth and Wendy Parmet look at normative obligations in a country, but focus more on the concept of health as a global public good as the generator of obligations to all persons, be they citizens or undocumented migrants. They suggest that "health satisfies the critical features of a public good": non excludability and non rivalry. In other words, ensuring one person's health does not exclude others from health. They state "the health of others is a good for all."

Illingworth and Parmet go on to examine the concept of solidarity as a mechanism for understanding why undocumented migrants should have healthcare access. In a move, much like Dwyer's, they state that because immigrants and citizens "dwell together", duties of solidarity are generated, based upon inter reliance of the social duties and labour that each perform. Heather Widdows and Herjeet Marway also draw upon the idea of global public goods. They suggest that although undocumented migrants may indeed have the right to health, appealing to health as a global public good, creates a more powerful practical and philosophical mechanism for change, as it emphasises that good health for specific populations in fact protects the health of all. They claim this alternative approach has advantages over a rights-based approach as it is non-oppositional and appeals to interests of non-migrants as well as migrants.

Gillian Brock utilises cosmopolitanism to address the issue of remedial responsibilities owed to developing countries by wealthy nations. In particular she locates the link between the "brain drain" and poverty, and how this in turn is connected to the movement of peoples. As goods like health and education flow from developing countries to wealthy ones, so do populations. Brock suggests that one way in which positive duties might be fulfilled is "through addressing the health needs of non-compatriots who are residents of our community." (p.8) Brock, like Dwyer and Illingworth and Parmet, asserts that claims for access to health care are also generated by the contribution that irregular migrants make, through, for example, labour and tax.

Verina Wild also looks to cosmopolitan theory, but seeks to spell out the normative foundations that might lead to access to healthcare that are often left without explication. In so doing she examines two central claims; namely that 1) health is a primary good that generates a cosmopolitan obligation for meeting health needs for each human being equally, and 2) that while for some states universal access to basic healthcare cannot be met, for wealthier countries, it is easily practicable to provide healthcare for all within its borders, 
regardless of citizenship status. To test these claims she analyses a number of possible objections.

Wild suggests that the "theoretical approach that comes closest to a cosmopolitan account for providing healthcare for migrants are theories of domestic justice." These theories, however, do not account for refugees and migrants without being refocused towards cosmopolitanism.

Mark A. Hall and Jacob Perrin turn to social justice to address issues related to health care access. The authors examine many different positions between the right to minimalist healthcare, and full access regardless of status. Some of these rely on pragmatic considerations and others on more principled philosophical accounts. They turn to Michael Walzer's Spheres of Justice, and suggest that more work is needed concerning which sphere healthcare for these populations belongs to before any consensus can be reached.

The tension between needs and rights of migrants - particularly of those that are rendered most vulnerable - and the protection of the legitimate interests of the receiving countries will most probably increase in the future due to armed conflicts, increasing economic inequalities and issues related to climate and the unequal distribution of resources such as food, water and energy. To the best of our knowledge this special issue is the first that discusses in depth the philosophical underpinnings of migrants' access to health care. We hope to stimulate discussions among scholars that will expand on this first step and that will ultimately find ways to facilitate ethical values in the provision of health care to migrants that are rendered vulnerable. However, access to health care is only one of many urgent but under researched ethical issues related to migration and health.

At our conference at the Brocher Foundation the participants agreed that a complex array of factors are required to be taken into account or explored further when discussing ethics of migrants' health in the professional health care context, within health care systems, and during periods of movement and settlement. The following are just some of these issues:

- Systematic unpacking of ethically relevant questions. So far there are only isolated initiatives to discuss ethical questions, but a closer inspection of the theme will reveal that many questions are not asked or deserve much closer scrutiny (e.g. the physician's role during hunger strikes of migrants, responsibility for health care during transit, the ethics of health screening at the border, the justifiability of discrimination in the health care towards migrants, the reconciliation of health obligations with migration policy, etc.)

- An understanding of underlying definitions, and their problems, and a careful use of labels such as "migrant" and "refugee". Migration should not be characterized by a false dichotomy between "us" and "them", but should be considered in terms of circumstances that put a person into situations affecting her or his health.

- Knowledge and further development of conceptual work e.g. on vulnerabilities, power relations, oppression, victimization, empowerment in order to increase the understanding of both theory and practice of migrants' health. 
- An understanding of the historical and generational dimension of migration, and an exploration of new trends and increasing power imbalances as relevant to bioethics and public health ethics.

- The necessity of normative ground work to strengthen the foundation of specific ethical deliberation.

- A balanced discussion of rights, needs, duties and responsibilities, encompassing both individuals and the societal, international and the global perspective.

- Empirical research using qualitative and quantitative methods and that is ethically informed and methodological reflections on research with different migrant groups, in order to deal with delicate questions of informed consent, stereotyping and the potential increase of discrimination.

- Deliberation on context based scenarios, in order to understand better and do justice to specific ethical problems (undocumented migrants in high income countries, refugees in lowincome countries, nomadic populations, internal migrants, etc.).

- The crucial role of health care professionals, as they can have dual loyalties to the individual and to the society which might lead to ethically problematic situations.

- The crucial role of ethics teaching concerning the topic of migration, which should be included in health curricula.

- A close interrelation with the disciplines of international and domestic law to increase a more thorough understanding of the issues at hand and in order to evaluate and develop ethical policy.

A recognition of migration is one of the defining issues of the $21^{\text {st }}$ century. And so, with this special issue we hope to stimulate more ethical discussions on the health of migrants, and especially of those that are rendered most vulnerable. We would not only like to see migrants' health receiving a place on the agenda of bio- and public health ethicists, but that bioethics and public health ethics situate themselves self-evidently and explicitly within a migrating world, and acknowledge in every ethical endeavour that is undertaken, that migration and the ethical challenges it raises, defines the world we live in.

\section{Acknowledgments:}

We would like to express our deepest gratitude to the participants at our conference at the Brocher Foundation in 2013 for the intense discussions that - among many other positive effects - led to the joint collection of issues listed in this editorial.

UNHCR, (2014). War's Human Cost. UNHCR Global Trends 2013. available from: http://www.unhcr.org/5399a14f9.html [last accessed 20 May 2015] 
United Nations, (2014). General Assembly. $69^{\text {th }}$ Session. International Migration and Development. available from: http://www.iom.int/sites/default/files/UN_Documents/69th_Session/N1448855.pdf accessed 20 May 2015]

[last 